\title{
When A Pandemic Knocks on a Restoration Ecologist's Door
}

\author{
Steven N. Handel
}

T he focus shifts from the restoration of habitats to the struggle to secure public health. We spend years advocating for people to pay attention to nature and then, unbidden, malevolent nature knocks on our door. The coronavirus pandemic has changed our world and we sit, isolated, frightened of our neighbors, unsure how our world is being redesigned by an invisible viral architect. Perhaps our dedication to restoration ecology work should be recalibrated. Just how important is it to reframe our cities with more green spaces and species, to border our farms and rural parks with restored meadows and edge habitats?

The link between restoration ecology and public health should not be obscure. Our field has long advanced the importance of ecological services for human health, focusing on rather obvious and appealing benefits such as clean and cool air, regulation of groundwater supply, and habitats for pollinators to enhance food security. The deadly coronavirus of 2020 ups the stakes. Should restoration ecology projects garner attention during this time of plague?

There is an increasing body of data showing that high biodiversity may lessen the frequency of parasitic attacks. Although not all parasite-host interactions have been explored, large meta-analyses of this relationship show a "dilution effect," a correlation between higher biodiversity and decreased parasitism and even herbivory to our crop plants and habitats. Using another popular idiom of today's trouble-prone world, biodiversity can increase resilience against the appearance and power of some diseases and protect the human population against another wave of sickness.

Many academic ecologists think of resilience in terms of Paul Ehrlich's rivet metaphor for biodiversity: the more species we have the greater the chance that ecological function is maintained, just as more rivets on a plane's fuselage increase the chance that a wing will not fall off. But resilience can also be framed as a barrier against new stresses. More species in our surrounding habitats become living barriers to separate humans from microbial enemies.

Ecological Restoration Vol. 38, No. 3, 2020

ISSN 1522-4740 E-ISSN 1543-4079

(O2020 by the Board of Regents of the University of Wisconsin System.
When a microbial wave appears and rises, the presence of many species and habitats can lessen the intensity of its insult against humanity. Even for the current coronavirus strain, there are reports that people with a lower number of viral particles in their blood have a greater chance of recovery really than those with a high titer. The immune system is not overwhelmed.

A framework outlined by Mukherjee (2020) addresses public health supply chains, but it can be transferred to the actions of the restoration ecology community. In understanding and organizing a supply chain, disruptions occur when there is an episodic shortfall of a critical component or resource. The functioning of the supply chain may persist despite the shortfall if it has a reasonable "time to survive," a resilience to persist through time until that resource becomes available again. In our ecological world one can imagine analogous situations. If a pollinator becomes scarce, the plant species may still survive if alternative mutualists are present or the plant's life history dynamics can tolerate the loss of seed set for a few years because the death rate of mature plants is relatively low. Their "time to survive" is long enough to tolerate a break in the reproductive biology chain.

There is also a "time to recover," the amount of time needed to rebuild the availability of the critical supply whose availability had crashed. In the world of public health this might mean how long will it take to build a new vaccine development factory when your traditional supplier's manufacturing base was destroyed by an earthquake or political upheaval. Another trauma that is being experienced during the current coronavirus pandemic is the breaking of the transport supply chain as oceanic trade decline closure of port and air transport facilities are rampant. When will the world be safe enough to allow the movement of critical medical supplies, from masks to pharmaceuticals?

In the restoration world we also struggle with the time to survive and a time to recover. We can design and build a new habitat, but will the plant species persist until the mutualists, whether in the soil or in the air, appear? Eventually these mutualists may be added as a functional layer to our hydrology redesign and planting regimes, but will the recovery time be fast enough to supply ecological functions 
that we need? Will our heartfelt restoration efforts shrivel and fail before the full recovery of community ecology resources?

These operational concerns of the ecologist are present in each of our projects. The links between public health and restoration ecology action are real and, in many situations, may be critical to our human communities. The daily trauma of sickness and death in our 2020 world may overshadow the importance of our fieldwork but it must not erase the reality that our restoration actions can play a role in escaping from the death toll around us.

Our work is so hard. We organize, cajole landowners and regulators, fund the work, construct then manage the project. We need so much organization to succeed and serve our communities. Many of us now sit isolated, quiescent, waiting for our local communities to become secure again. Restoration work is not tangential to the public health crisis. Healthy habitats help parry disease. They are units of the building blocks for a safer world.

\section{Recommended Readings}

Civitello, D.J., J. Cohen, H. Fatima, N.T. Halstead, J. Liriano, T.A. McMahon, et al. 2015. Biodiversity inhibits parasites: broad evidence for the dilution effect. Proceedings of the National Academy of Sciences 112:8667-8671.

Curriero, F.C., K.S. Heiner, J.M. Samet, S.L. Zeger, L. Strug and J.A. Patz. 2002. Temperature and mortality in 11 cities of the eastern United States. American Journal of Epidemiology 155:80-87.

Mukherjee, S. 2020. After the storm. New Yorker May 4:24-31.

Patz, J.A., P. Daszak, G.M. Tabor, A.A. Aguirre, M. Pearl, J. Epstein, et al. 2004. Unhealthy landscapes: Policy recommendations on land use change and infectious disease emergence. Environmental Health Perspectives 112:1092-1098.

Vittor, A.Y., R.H. Gilman, J. Tielsch, G. Glass, T.I.M. Shields, W.S. Lozano, et al. 2006. The effect of deforestation on the humanbiting rate of Anopheles darlingi, the primary vector of falciparum malaria in the Peruvian Amazon. The American Journal of Tropical Medicine and Hygiene 74:3-11.

Wood, C.L., K.D. Lafferty, G. DeLeo, H.S. Young, P.J. Hudson and A.M. Kuris. 2014. Does biodiversity protect humans against infectious disease? Ecology 95:817-832.

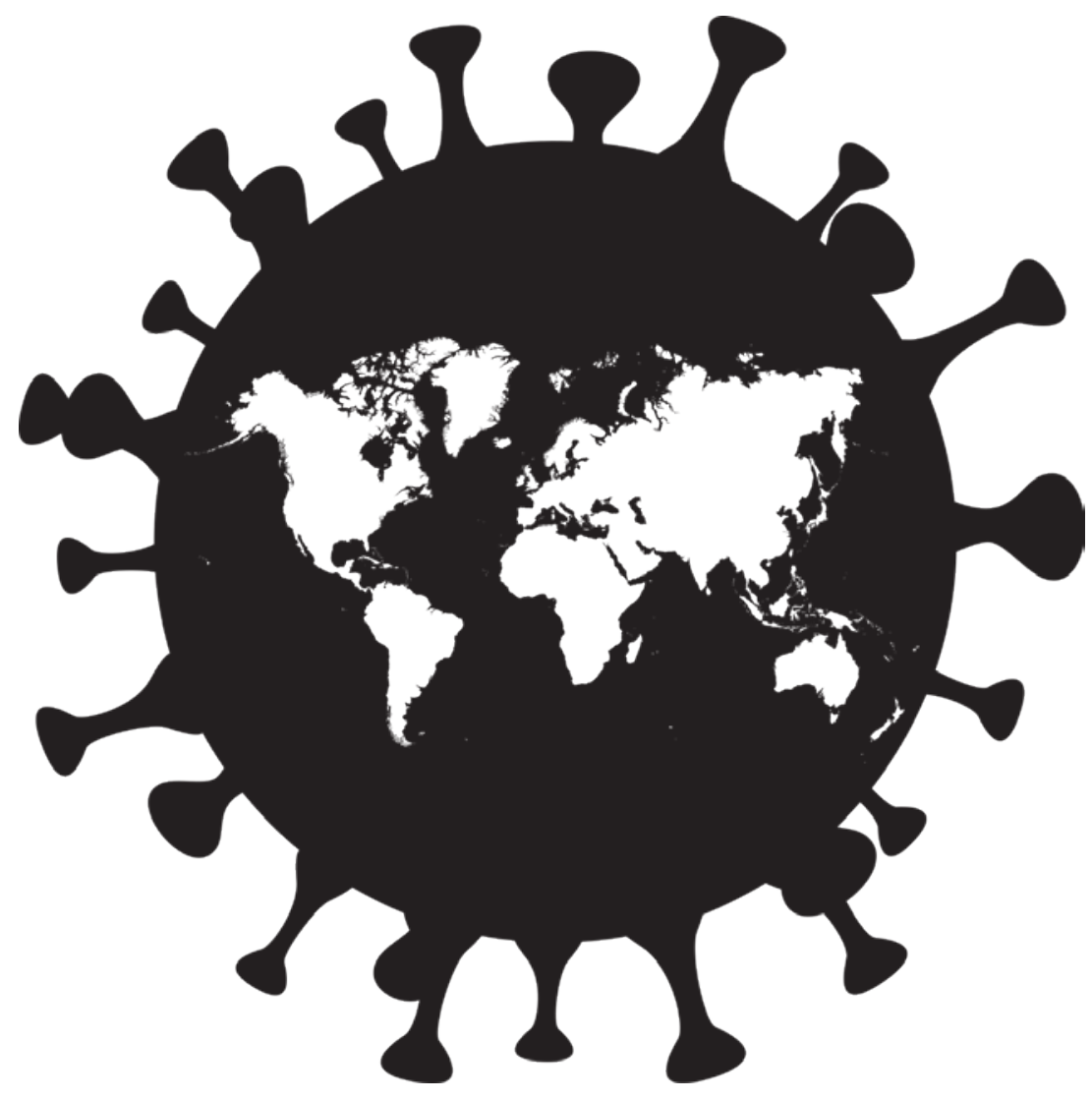

Coronavirus. Pixabay. 